\title{
A NEW COLOUR REACTION FOR ALOES.
}

By C. E. STACY.

(Read at the Meeting, March 1, 1916.)

A PINK coloration sufficiently delicate to detect one part of Barbadoes aloes in 10,000 is produced by the addition of a freshly prepared solution of potassium ferricyanide to the cold aqueous solution of the aloes. If excess of either test solution or reagent is employed no colour is produced, and it is necessary that the strength of the reagents should be roughly proportional to the strength of the solution to be tested.

The colour is permanent, and is rendered apparent more rapidly by heating just to boiling, as in most cases the colour takes from five to fifteen minutes to appear. On treating Barbadoes aloes with petroleum ether, benzene, and chloroform, minute quantities of the reacting substance are removed, but none by ether or ethyl acetate, and, after the removal of the ordinary principles of aloes (aloin, emodin, etc.), the bulk of the substance causing the pink coloration is left behind.

In somewhat more concentrated solutions the colour is a deep crimson, and in 1 per cent. or upwards a blood-red.

Socotrine and Cape aloes do not give this reaction, but give an emerald-green colour, which is not nearly as delicate as the Barbadoes reactions, but is sufficient for the detection of 1 in 250 of Socotrine aloes, and is less delicate with Cape aloes. Commercial aloin also gives a green colour with this reagent.

No reaction is given with extracts of cascara sagrada or rhubarb, so that the colour is not given by frangulin, frangulic acid, or chrysophanic acid.

The chief value of the test consists in its ability to distinguish Barbadoes aloes from the other varieties and from commercial aloin in medicinal preparations.

I was unable to obtain specimens of Curaçoa or Natal aloes, but the three varieties tested are, I understand, the only ones used ordinarily in medicine, at least in this country.

The colour is destroyed by acids. Small quantities of alkalis intensify the reaction, at the same time modifying it by introducing a brown tint. Large amounts of alkalis destroy the colour.

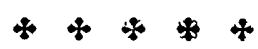

